\title{
Müșteri Hizmetleri Yönetiminde Yapay Zeka Temelli Chatbot Geliştirilmesi
}

\author{
İsmail İşeri ${ }^{*}$, Özkan Aydın², Kaan Tutuk ${ }^{3}$ \\ 1* Ondokuz Mayıs Üniversitesi, Mühendislik Fakültesi, Bilgisayar Mühendisliği Bölümü, Türkiye (ORCID: 0000-0002-0442-1406) \\ ${ }^{2}$ Selekt Bilgisayar İletişim Ürünleri İnşaat Sanayi ve Ticaret Limited Şirketi, Türkiye \\ ${ }^{3}$ Selekt Bilgisayar İletişim Ürünleri İnşaat Sanayi ve Ticaret Limited Şirketi, Türkiye
}

(International Symposium on Multidisciplinary Studies and Innovative Technologies (ISMSIT) 2021 - 21-23 October 2021)

(DOI: 10.31590/ejosat.1025380)

ATIF/REFERENCE: İşeri, İ., Aydın, Ö. \& Tutuk, K. (2021). Müşteri Hizmetleri Yönetiminde Yapay Zeka Temelli Chatbot Geliştirilmesi. European Journal of Science and Technology, (29), 358-365.

$\ddot{\mathbf{O} z}$

Chatbot yani sohbet robotu; kullanıcıların bilgisayar ile sesli veya yazılı olarak iletişime geçtĭgi bir uygulamadır. Günümüzde chatbotlar yaygın olarak birçok sektörde kullanılmaktadır. Chatbotlar kural tabanlı ve makine öğrenme temelli olmak üzere temel olarak iki şekilde tasarlanmaktadır. Bu çalışmada gerçek bir işletmenin çağrı merkezi işlemlerini yönetebilmek adına makina öğrenimi ile çeşitli doğal dil işleme (NLP) teknikleri kullanılarak bir chat bot tasarımı gerçekleştirilmiştir. Bu sohbet robotunun geliştirilmesindeki temel amaç kullanıcıların firma veya firma ürünleri hakkındaki soru veya soruları karşısında bir çalışana ihtiyaç duymadan hızlı ve efektif bir şekilde çözüm bulmasıdır. Bu sohbet robotunda kullanıcı sorular sorarak girdiler oluşturmaktadır. Bu girdilere yanıt olarak ise veri setinde uygun alan altındaki oluşturulmuş responses alanı cevap olarak kullanıcıya dönmektedir. Veri setinde ise niyet, bu niyete ait olan patern ve verilmesi gereken cevaplar bulunan bir json dosyası kullanılmaktadır. Veri setini oluşturan patern ve cevaplar firmanın sıkça sorulan sorular (S.S.S) bölümüyle birlikte, firmanın çağrı merkezine gelen telefon konuşmaları ve whatsApp müşteri hizmetleri hattındaki veriler ile oluşturulmuştur. Eğitilen model 32 gün boyunca her gün belli saat aralıklarında canlı olarak devreye alınmış ve chatbotun sorulan sorulara karşın verdiği cevapların oldukça yüksek olduğu görülmüştür.

Anahtar Kelimeler: Chatbot, Yapay Zeka, BertModeli, NLP

\section{Artificial Intelligence Chatbot Development in Customer Service Management}

\begin{abstract}
It is an application where users communicate with the computer by voice or in writing. Today, chatbots are widely used in many industries. Chatbots are basically designed in two ways: rule-based and machine learning-based. In this study, a chat bot design was carried out using machine learning and various natural language processing (NLP) techniques in order to manage the call center operations of a real business. The main purpose of the development of this chat robot is to find solutions quickly and effectively without the need of an employee in the face of questions or questions about the company or company products. In this chatbot, the user creates inputs by asking questions. In response to these inputs, the responses field created under the appropriate field in the data set returns to the user in response. In the dataset, a json file is used with the intent, the pattern belonging to this intent and the answers to be given. The pattern and answers that make up the data set were created with the frequently asked questions (FAQ) section of the company, phone calls from the company's call center and data from the whatsApp customer service line. The trained model was activated live at certain hours every day for 32 days and it was seen that the answers given by the chatbot were quite high despite the questions asked..
\end{abstract}

Keywords: Chatbot, Artificial Intelligence, BertModel, NLP

${ }^{1}$ Sorumlu Yazar: Ondokuzmayıs Üniversitesi, Mühendislik Fakültesi, Bilgisayar Mühendisliği Bölümü, Samsun, Türkiye, ORCID: 0000-0002-04421406, ismail.iseri@omu.edu.tr 


\section{Giriş}

Sohbet botları, metin yoluyla veya ses yoluyla kullanıcıları ile etkileşimde olan kendi başlarına ve bir insanın yardımına ihtiyaç duymadan bir çok görev ve görevleri yerine getirmek için oluşturulmuş bir yapay zeka yazılımıdır.

Sohbet botlarının bugünlere kadar uzanan yolculuğu ilk olarak 1950 yılında İngiliz matematikçi, bilgisayar bilimcisi ve kriptolog olan Alan Turing'in Mind adlı felsefe dergisinde yayınladığı ünlü makalesi COMPUTING MACHINERY AND INTELLIGENCE makalesi [1] ile başlamıştır.

Yıllar geçtikçe ilerleyen teknoloji, buluşlar ve insanların ihtiyaçlarıyla bugünlere kadar gelmiş ve halen gelişimini sürdürmektedir. Bilgi iletişim teknolojilerinin sonucu olarak ortaya çıkmış olan chatbotlar işletmelerin, şirketlerin, fabrikaların müşteriyle olan ilişkilerini yönetmede yeni metotlar sunmaktadır. $\mathrm{Bu}$ sebepten dolayı chatbotlar ve bu chatbotların oluşumunda, faaliyetinde süregelen yazılım ve yazılım araçları ticari bir öğeye bürünmektedir. Yapılan araştırmalarda ise kullanıcıların \%68 gibi bir çoğunluğu bir firma canlı desteğiyle iletişime geçmek yerine chatbotlar ile iletişime geçmeyi tercih etmekte [2] Ve kullanıcılar bu araştırmada iletişim için bir insanla etkileşimde olmanın önemli olmadığını ve chatbotun iletişimdeki en kolay yol olduğunu belirtiyor. Başka bir araştırmada ise 5 yıl içerisinde chatbotların bankalara kullanıcılarla iletişimi başına $0,5-0,7$ Dolar arasında bir miktarda tasarruf sağlamasını beklendiğini söylemektedir. [3] Bu araştırmalar ışığında chatbotların gelecekte daha çok kullanılacağı bu pazarında büyümesiyle birlikte chatbotların arkasındaki teknoloji, araçlar, modellerde orantılı bir şekilde değişim ve gelişime uğrayacağı aşikardır. Bir chatbotun birçok işlevi bulunmaktadır. Kullanıcılarına data toplamak, göstermek, hava durumu tahminlerinden haberdar etmek, bankacılık işlemlerinde isteklerini yerine getirmek, sohbet edebilmek, günlük dijital ortamdaki işlerini yaptırmak, bir kullanıcının firmayla olan soru veya sorunlarını hızlı bir şekilde çözüme kavuşturmak, gibi birçok özelliğini sayabiliriz. İnsanların günümüzde neredeyse her alanda önüne çıkan bu chatbotlar için genellikle kullanılan iki türünden söz edebiliriz. Bu chatbotlardan ilki kullanıcı arayüzünün arka tarafında önceden oluşturulmuş olan kurallara eylemlere tabii olan kural tabanlı veya görev tabanlı chatbotlardır. $\mathrm{Bu}$ chatbotlarda genel olarak sinıflandırma algoritmaları kullanarak oluşturulmaktadır. $\mathrm{Bu}$ chatbot uygulamalarında, $\mathrm{n}$ adet konu ve $\mathrm{n}$ adet cevabın bir listesini içermektedir. Uygulamada, sınıflandırılacak olan girdinin veya konunun tahminleme sonucunda düşük bir olasılığı çıktığında kullanıcıdan daha özel ve sorununu veya sorusunun ifadesinde spesifik tanımlar kullanmasını soruyu tekrar etmesi istenmektedir.

Diğer chatbot türünde ise daha karmaşık ve daha gelişmiş bir yap1 bulunmaktadır. Kullanıcıya verdiği yanıtlar daha kişiselleştirilmiş ve daha uygun olabilmektedir. Özel bir Tekrarlayan Sinir Ağı olan ve metin üretme gibi oldukça sık kullanılan LSTM ile kullanıcı girdilerini daha iyi anlayabilmekte ve işlemler sonucunda kullanıcıya en makul, en mantıklı yanıtı döndürmektedir. Chatbot alanında öne çıkan akademik çalışmalar ve uygulamalardan bahsedecek olursak; Ming Hsiang Su, Chung Hsien Wu, Kun Yi Huang, Qian Bei Hong, Hsin Min Wang grup üyeleri tarafınca yapılmış olan bu çalışmada yaşlılar için yapılmış olan bir chatbot bulunmaktadır. Bu çalışmada Multimedya İnsan
Makine İletişimi (MHMC) isimli laboratuvar tarafından toplanan bir duygusal veri tabanı kullanılmaktadır. Çalışmada LSTM tabanlı çok katmanlı bir gömme modeli kullanılmıştır [4]. Başka bir çalı̧̧ma ise Diyalog sistemleri tasarlama: Ortalama, huysuz, göz atmada alaycı chatbot $\mathrm{Bu}$ yapay zeka chatbot araştırma makalesinde, etkileşim oluşumu sürecinden alaycı ve esprili cevaplar oluşturan derin öğrenmeyi temel alan bir diyalog sistemini araştırmaktadır. Araştırmacılar, ortalama, huysuz, alaycı chatbotun temeli olan 3000 soru-cevap çiftinden oluşan özenle seçilmiş bir veri seti üzerinde bir seq2seq modeli eğitmektedirler [5]. Bir diğer çalışmada ise Bir Üniversite Alışveriş Merkezi için E-Ticaret Chatbotunun Geliştirilmesi konusu üzerinde durulmuştur. Geliştirilen bu chatbot'un amacı, kullanıcıların alışveriş merkezini ziyaret etmeden önce almak istedikleri ürünler hakkında bilgi almak ve ürünler için online ödeme yapmak gibi kolaylıkları chatbot ile zahmetsiz bir şekilde sağlamasıdır [6]. Diğer yapılmış bir çalışma ise seq2seq LSTM Modeli ile Telegram Bot Uygulaması'dır. Bu çalışmada araştırmacılar LSTM (Uzun Kısa Süreli Bellek) ve seq2seq modeli ile bir telegram mesajlaşma uygulamasında kullanılmak üzere bir bot geliştirmektedirler. Bu çalışmada Uzun Kısa Süreli Bellek kullanılması daha sonraki konuşma eylemini tahminlemek için konuşma geçmişine geri dönüş yapılabilmesini sağlamıştır [7]. Diğer bir çalışma ise İş dünyasındaki chatbot gelişmeleridir. Bu çalışma, chatbot'un işletmeye olduğu kadar işletmeye de nasıl etki ettiğini, chatbot'un ne gibi özelliklere ihtiyaç duyduğunu ve iş ortamında uyumlu olabilmesi için chatbot'un nasıl geliştirilmesi gerektiğini belirlemeyi amaçlamaktadır [8]. Kronik hasta desteği için mikro hizmet sohbet robotu mimarisi çalışmasıyla ile kronik hastalıkları veya komorbiditeleri olan hastaların, durumlarını takip edebilen, spesifik bilgiler sağlayan, ilaca uyumu teşvik eden vb. sohbet robotlarından en fazla fayda sağlayabilen. Bu işlevleri gerçekleştirmek için sohbet robotlarının uygun bir temel yazılım mimarisine ihtiyacı olduğunu ve bu yazıda, kronik hasta desteği için üç sütuna dayanan bir sohbet robotu mimarisi tanıtmaktadırlar [9]. Bu çalışma Finansal sürdürülebilirlik için sohbet robotlarıyla alakalıdır. Çalışmada yapay zekanın (AI) uygulandığı endüstri talebi için teknoloji etkinliği incelemektedir [10]. Bir Konuşma Aracı: Chatbot. Bu makale, bir Chatbot sisteminin tasarımını ve uygulamasını ele almaktadır. Ayrıca Chatbot'ların yararlı olabileceği başka bir uygulamayı ve Chatbot tasarlarken kullanılan teknikleri incelemektedir [11]. ALICE sohbet robotu: Denemeler ve çıktılar. Bu makale, ALICE sohbet robotuna, onun AIML formatına ve bir korpus yaklaşımına dayalı olarak otomatik olarak farklı ALICE prototipleri oluşturmaya yönelik deneyimlere genel bir bakış sunmaktadır [12]. Gençlerle Birlikte ve Gençler İçin Akıl Sağlığı ve Refahı Sohbet Robotu Geliştirmek isimli makalede ise Chatbot'un nasıl geliştirildiği tartışılmaktadır ve bu dijital araçtan yararlanacak kilit paydaşlar olan gençlerle katılımcı, ortak tasarım sürecini vurgulamaktadır. Görüşmelerden ve anketlerden elde edilen araştırmalar, Chabot kişiliğinin yaratılması ve karakter tasarımı hakkında bilgi verilmektedir [13]. Sağlık Sohbet Robotu isimli çalışmada hastaların sohbet robotu ile etkileşime girmesine yardımcı olmaktadır. Bu sağlık hizmeti sohbet robotu, kullanıcıların sorgularını yanıtlama konusunda rahat olmalarını sağlamak için çevrimdışı moda da sahiptir [14]. Bilgi güvenliği için bir chatbot bu yazıda bilgi güvenliğinde danışman olarak görev yapan bir chatbot önerilmiştir. Önerilen danışman, json dosyası içeren bir bilgi tabanı kullanır. Bu tür bir chatbot'a sahip olmak, birçok kullanıcıya farklı konularda bilgi güvenliği uzmanlarından farklı 
görüşlere dayalı doğru tavsiyeler sunarak bilgi güvenliği alanında farkındalık yaratmak gibi birçok özellik sağlamaktadır [15]. Uzaktan eğitim asistanı olarak bir chatbot tasarımı EconBot adlı sohbet robotu veya sohbet robotu biçiminde bir sanal asistan olan , 2017'den itibaren öğrencilerin kullanımına sunuldu. Özellikleri ve işlevleri, kullanışlılığının değerlendirilmesi ve bu tür teknolojik yeniliklerin uygulanmasında öğretmenlerin rolünü vurgulamaktadır [16]. Diana'ya Sor: Suyla ilgili afet yönetimi için anahtar kelime tabanlı bir sohbet robotu sistemi. Bu çalışmada afet yönetimi, afetle ilgili verilerin karmaşık özellikleri nedeniyle zor ve meşakkatli kabul edilmiştir. Bu problemle başa çıkmak için bu araştırma, suyla ilgili bir felaket veritabanı, bir kullanıcı niyet mekanizması ve sezgisel bir mobil cihaz tabanlı kullanıcı arayüzü ile bir sohbet robotu sistemi geliştirilmiştir. Böyle bir sistemle kullanıcılar, önerilen chatbot'a doğrudan sorarak veya görüntü tabanlı menüleri çalıştırarak karar vermek için ihtiyaç duydukları önemli verilere veya bilgilere erişilebilmektedir [17]. Sosyal mevcudiyet ve chatbot hatalarının güvene etkisi. Bu makale, Yapay Zeka (AI) sohbet robotlarının dijital alanda müşterileri destekleyerek olumlu değişim yaratma potansiyelini araştırmaktadır [18]. GameBot: Spor oyunları için görselleştirme ile güçlendirilmiş bir sohbet robotu GameBot, kullanıcının istatistiklerle ilgili sorularına doğrudan yanıtlar ve spor hayranlarının istatistiklerle ilgili soruları için destekleyici bağlam olarak veri görselleştirmelerinin kullanımını içermektedir [19]. Chatbot tabanlı turist önerileri: $\mathrm{Bu}$ yazıda, insanların otel rezervasyonu yapmak, gezi planlamak ve görülmeye değer ilginç yerler istemek amacıyla metinsel olarak iletişim kurmasına olanak tanıyan e-turizm için bir Chatbot'un arkasındaki temel yöntem ve teknolojileri sunulmakta [20]. Bu çalışmadaki amacımız firmadan aldığımız Sıkça sorulan sorular (S.S.S) bölümündeki firma kullanıcılarının firmaya sorduğu soruları, öğrenmek istedikleri, aklına takılan sorular ve cevaplarından oluşturduğumuz veri setini kullanarak görev tabanlı bir biçimde derin öğrenme algoritmaları ile modelimizi eğitip kullanıcılara cevaplar iletmekteyiz. Makalenin ikinci bölümünde kullandığımız materyallerden, üçüncü bölümde ise kullandığımız yöntemlerden, dördüncü ve beşinci bölümünde uygulama ve sonuç kısmından bahsedilecektir

\section{Materyal ve Metot}

\subsection{Veri Seti}

Çalışma kapsamında Samsun'da yer alan bir teknoloji firmasının sıkça sorulan sorular (S.S.S) bölümünde yer alan soru ve cevaplar, firmanın çağrı merkezine gelen telefon konuşmaları ve whatsApp müşteri hizmetleri hattındaki veriler kullanılarak toplam 1000 adetlik başlangıç bir veri seti oluşturulmuştur. Model eğitiminde kullanılacak veri setinin yapısı; json formatı içerisinde intents, tag, patterns ve responses kısımlarından oluşmaktadır. Intents en dışta bulunan kısım olarak içerisinde her bir kısım için ayrılmış bölümleri tutmaktadır. Tag'ler yani kategoriler içinde bulunan verileri başlıklar şeklinde kategori etmektedir. Patterns'ler ise kategorilerin içerisindeki soruları ve son olarak ise responseslar kategorilerin altında bulunan soruların cevapların tutmaktadır. Şekil-1' de veri kümesinden bir kesit görülmektedir.

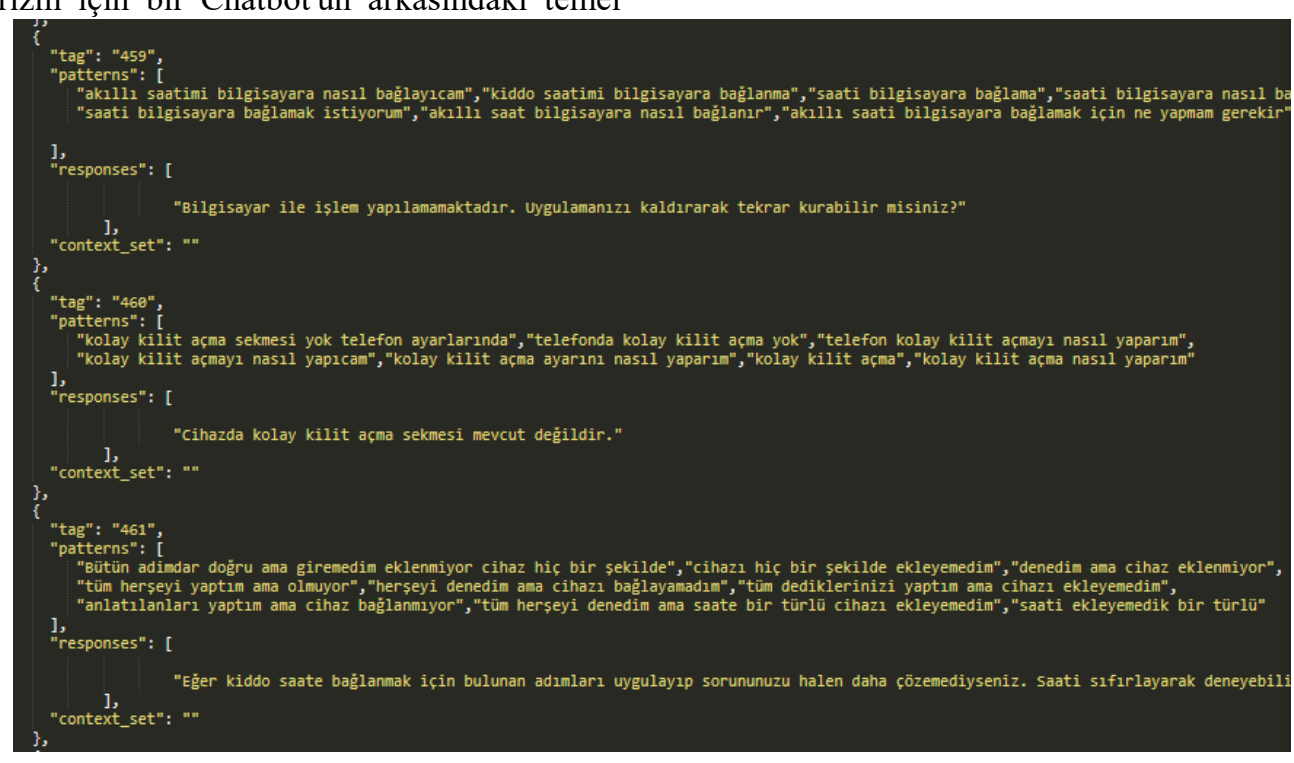

Şekil 1. Veri Setinden Kesit

\subsection{Kullanılan Platformlar ve Araçlar}

BERT siniflandirma ile chatbot projesinde Google Colaboratory, pycharm gibi ortamlardan yararlanıld1. Tensorflow, keras, numpy, matplotlib, pandas, torch, transformers, selenium, pyodbc gibi python kütüphaneleri ve araçları kullanılmaktadır.

\subsection{Kullanılan Yöntemler}

Çalışmada Şekil-2' de yer alan iş akışı doğrultusunda bir yöntem izlenmiştir. İlk olarak Bert modelinde kullanılacak verilerin hazırlanması sağlanmıştır. Daha sonra Bert modelinin eğitilmesi ve eğitilen modelin whatsap üzerinden şirket web sayfasına bağlanması ve başarımlarının günlük olarak takip edilmesi sağlanmıştır. Çalışma kapsamında başlangıç veri kümesi ile eğitilen model 32 gün boyunca hergün şirket web sitesi üzerinden gerçek kullanıma alınarak oluşan yeni sorulardan oluşan veriler kaydedilmiş, modelin tekrar yeni sorularla eğitilmesi sağlanmıştır. 
Şekil 2. İ̧̧ akışl

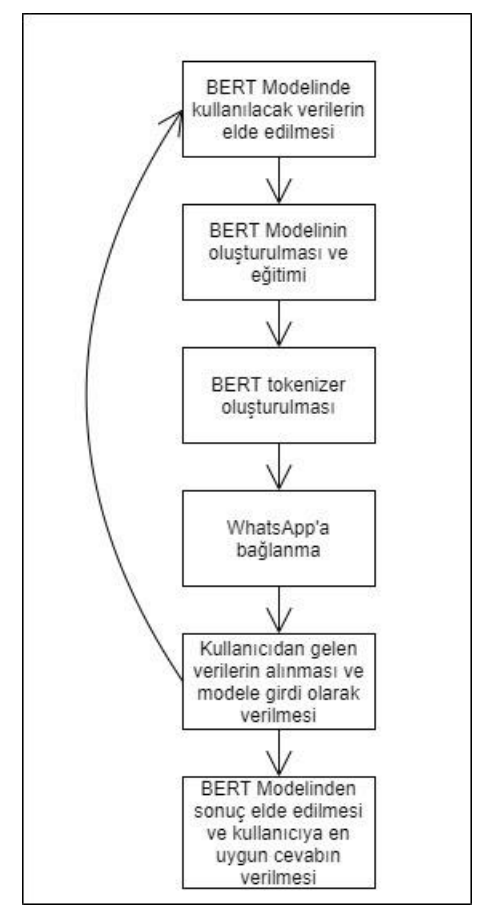

\subsubsection{BERT Modelinde Kullanulacak Verilerin Elde Edilmesi}

BERT sınıflandırma modelinde kullanılacak veriler; çağrı merkezi kayıtlarından oluşan ses dosyaları, whatsApp müşteri hizmetleri konuşmaları ve sıkça sorulan sorulardan oluşmaktadır. $\mathrm{Bu}$ verilerin toplamında oluşan soru cevap çiftleri json dosyasına birçok soruya karşılık bir çok cevaptan oluşmaktadır. Bu yapı kurulduktan sonra json dosyasında bulunan tagler arasında sınıflandırma gerçekleştirilecek duruma gelmektedir.

\subsubsection{BERT Modelinin Oluşturulması ve Eğitimi}

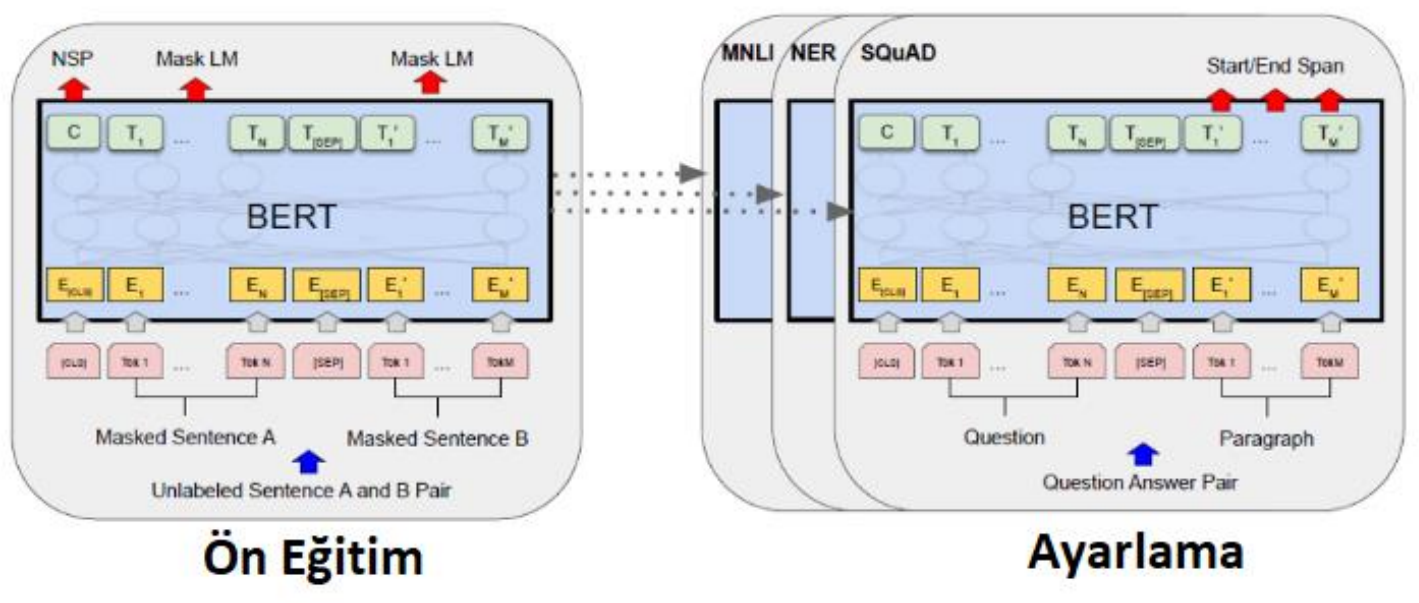

Şekil 3. Bert Modeli

Veri seti temel olarak hazırlandıktan sonra BERT modeli oluşturulma aşamasına geçilmektedir. BERT modeli Google tarafından 2018 yılında geliştirilmiştir. BERT modelinin diğer modellerden ayıran en temel özelliği verilen cümleyi hem sağdan sola hem de soldan sağa olacak şekilde incelemesidir. Bu sayede sınıflandırma işlemini daha etkili bir şekilde gerçekleştirmektedir. BERT modelinde bu özelliğinin dışında Masked Language Modeling (MLM) ve Next Sentence Prediction (NSP) isimleri verilen iki teknik daha kullanılmaktadır. MLM tekniğinde BERT modeli eğitim aşamasında ayrı ayrı alınan her bir cümlenin \%15 ini maskeleme yaparak geri kalan kısım tahminleme yapılması ile oluşmaktadır. NSP tekniği ise cümleler arasındaki ilişkilere bakılmaktadır. Bu sayede cümleler arasındaki bağlantıda test edilmiş olmaktadır. Çalışmada modelin oluşturulma aşamasında ilk olarak BERT modelinin daha hızlı çalışması için gpu destekleyen bir ortam hazırlanması sağlanmıştır. Bu ortama oluşturulan veri seti eklenmiş ve modele girecek şekilde düzenlemeler yapılmıştır. Model girmeden önceki son adımda ise test ve eğitim verisi olacak şekilde ayrılmış ve BERT sınıflandırma modeliyle eğitim sağlanmıştır.

\subsubsection{BERT Tokenizer Oluşturulması}

BERT modelinde kullanılan tokenizer işlemi, önceden elde edilmiş olan kelime haznesi ile birlikte model eğitimindeki cümleleri öğelerine ayırmak için kullanılmaktadır. Tokenizer işlemi ile birlikte cümleler öğelerine ayrıştırıldıktan sonra BERT sınıflandırma modeli ile sınıflandırma yapılabilmesi için gerekli tokenlar cümle başlarına ve cümle sonlarına eklenmektedir. Sabit uzunlukta bir vektör oluşturulmaktadır. Bu vektörün boyutu uzun ise kısaltma işlemi ile kısa ise tamamlama işlemi kullanılarak boyutu sabit uzunlukta tutulmaktadır.

\subsubsection{WhatsApp'a Bağlanma}

Oluşturulan model sonrasında modelin whatsapp mesajlaşma uygulamasında çalışması hedeflenmiştir. Whatsapp mobil uygulamasının web arayüzü olan Whatsapp Web ile etkileşim sağlanmıştır. $\mathrm{Bu}$ etkileşim internet tarayıcı altyapısıyla çalışan 
Selenium kütüphanesiyle gerçekleşmiştir ve Chrome tarayıcısı kullanılmıştır.

\subsubsection{Selenium Kütüphanesinin Genel Yapıst}

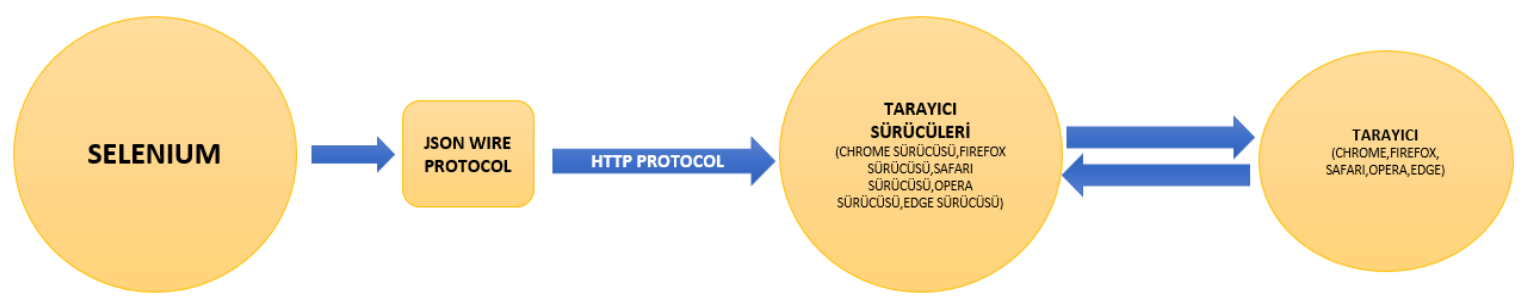

Şekil 4. Selenium Genel Yapı

Selenium kütüphanesi tarayıcı tabanlı çalışan bir otomasyon aracıdır. Tarayıcı tabanlı çalıştığı için web sitesinin direkt html yapısıyla bağlantı kurmaktadır. Bir web sitesinin html yapısındaki başlıkları, butonları, bölümleri tarayıcı tabanında gördüğü o kısımların yollarına ulaşarak gerçekleştirir. Xpath adı verilen bu yolları ve bu yollar ile neler gerçekleşeceğini Selenium'a Python Programlama Dili vasitasıyla gösterilmektedir. Selenium kodunun tamamı kendi içinde Json formatına dönüşür. JSON, Javascript Nesne Gösterimi anlamına gelmektedir ve sunucudan istemciye bilgi aktarma görevini üstlenir. JSON Wire Protocol, HTTP sunucuları arasında veri aktarımından birincil derecede sorumlu olmaktadır. Oluşturulan Json, tarayıcı sürücülerine HTTP Protokolü aracılığıyla sunulmaktadır. Her tarayıcının belirli bir tarayıcı sürücüsü vardır. Tarayıcı sürücüleri ilgili tarayıcılarla etkileşime girer ve tarayıcıdan aldıkları Json'u yorumlayarak komutları yürütür. Tarayıcı sürücüsü herhangi bir talimat alır almaz bunları tarayıcıda çalıştırır. Daha sonra yanıt HTTP yanıtı şeklinde geri verilir. Tarayıcı sürücüsü, isteği HTTP'den almak için HTTP sunucusunu kullanır. Tarayıcı sürücüsü isteği HTTP aracılığıyla tarayıcısına iletir. Tarayıcı da Selenium talimatlarını uygular. İşlem POST isteği ise, tarayıcıda bir eylemi web sitesiyle etkileşime girecektir. İşlem GET isteği ise, yanıt HTTP protokolü ile tarayıcı sürücüsüne iletilecektir. Tarayıcı sürücüsü de onu JSON Wire Protocol aracılığıyla kullanıcıya gönderecektir.

\subsubsection{Whatsapp Botunun Genel Yapist}

Selenium ile oluşturulan Whatsapp botu öncelikle whatsapp web sitesine bağlanmaktadır. Whatsapp web üzerinde telefon numarasına kayıtlı whatsapp mobil uygulaması üzerinden QR kod yardımıyla eşleme yapılmaktadır. $\mathrm{Bu}$ sistem farklı telefonların çalışmasını da beraberinde getirmektedir. Telefonlar QR kod eşlemesini gerçekleştiği için güvenlik üst düzeyde tutulmaktadır. Eşleme yapıldıktan sonra whatsapp web üzerinde oturum açılır ve gelen mesaj bildirimlerini taramaya başlar. Sonsuz bir döngü içerisinde taranan mesaj bildirimleri oluştuğu zaman bildirime tıklanır ve mesaj ekranına gider. Tespit edilen gelen mesaj kayıt altına alınır ve ilgili modele iletilir.

\subsubsection{Kullanıcıdan Gelen Verilerin Alınmast ve Modele Girdi Olarak Verilmesi}

WhatsApp aracılığı ile gelen verilerin her biri belli başlı değişkenlerde tutulmakta ve aynı zamanda veri tabanı kaydetme işlemi gerçekleştirilmektedir. Bu gelen veriler kullanılan BERT modelinin giriş kısmına verilmekte ve bu sayede içinde var olan veriler ile en uygun olan cevabı bulunması sağlanmaktadır.

\subsubsection{BERT Modelinden Sonuç Elde Edilmesi ve En Uygun Cevabin Verilmesi}

BERT modelinin eğitimi, whatsApp hattına entegresi ve bu sayede kullanıcılardan aldığımız verileri eğittikten sonra kullanıcının girdisini veri setinde hangi sınıf ile eşleştiğini veya hangi sınıfa daha yakın olduğunu tespit edilmektedir. Modele gelen girdiler ile yapılan tahminlemede, kullanıcıdan gelen girdilerin hangi sınıfa daha yakın olduğunu gösteren yüzdeler oluşturulmakta ve daha sonra en yüksek yüzdeye ait sınıfın yanıtlardan biri kullanıcıya sunulmaktadır. Ardından kullanıcıdan yeni bir girdi beklenmektedir. Bu şekilde yapımız sürekli işleyen bir sınıflandırma problemiyle kullanıcının soru ve sorunlarına en etkili ve efektif şekilde cevap vererek yardımcı olmaktadır.

\section{Deneysel Bulgular}

Gerçekleştirmiş olduğumuz çalışma sonucunda elde ettiğimiz bulgular aşağıda yer alan grafiklerle sunulmaktadır. $\mathrm{Bu}$ grafikler; günlere göre kullanılan modelleri ve veri sayılarını gösteren 'Kullanılan Modeller ve Veri Setleri' grafiği, günlere göre her bir soruya verilen cevabın başarı oranlarını gösteren 'Chatbot Günlük Başarı' grafiği ve son olarak ise günlere göre kaç soruya cevap verdiğini gösteren 'Chatbot Günlük Cevap' grafiğidir. Şekil-5 de 'Kullanılan Modeller ve Veri Setleri', Şekil6 de 'Chatbot Günlük Başarı' ve Şekil-7 da 'Chatbot Günlük Cevap’ görülmektedir. 


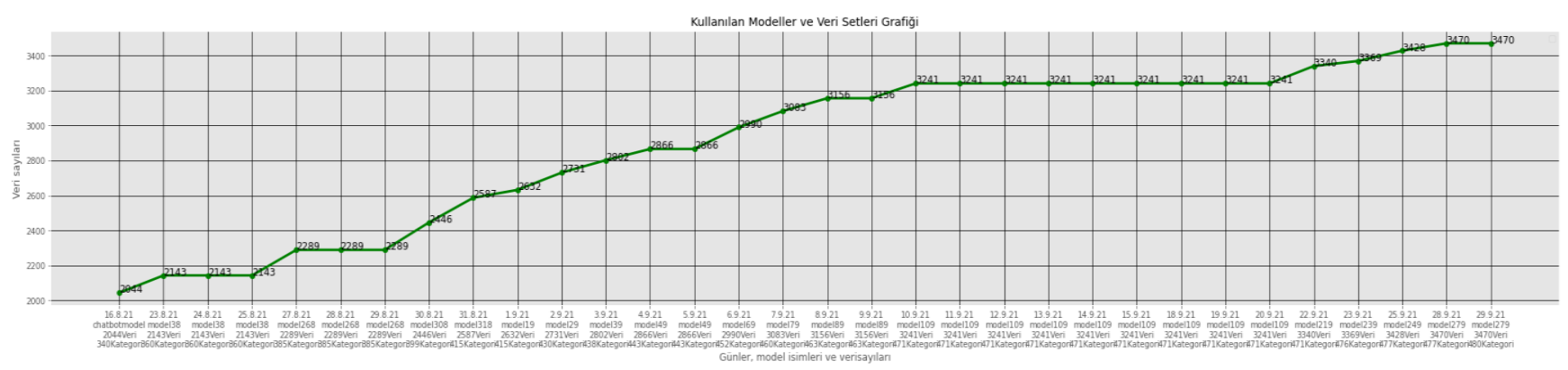

Şekil 5. Kullanılan Modeller ve Veri Setleri

Şekil 4'de bulunan grafik chatbotun eğitiminde günlük olarak kullanılan model isimlerini veri setlerinin büyüklüğünü, veri setinde kaç veri olduğunu ve kaç kategoriye sahip olduğu gösterilmektedir. 32 günlük süreçte modellere ait veri setlerinde sürekli bir atış gözükmektedir. Bu artışın sonucunda oluşan 32 günlük başarı grafiği ise Şekil-5 de gözükmektedir.

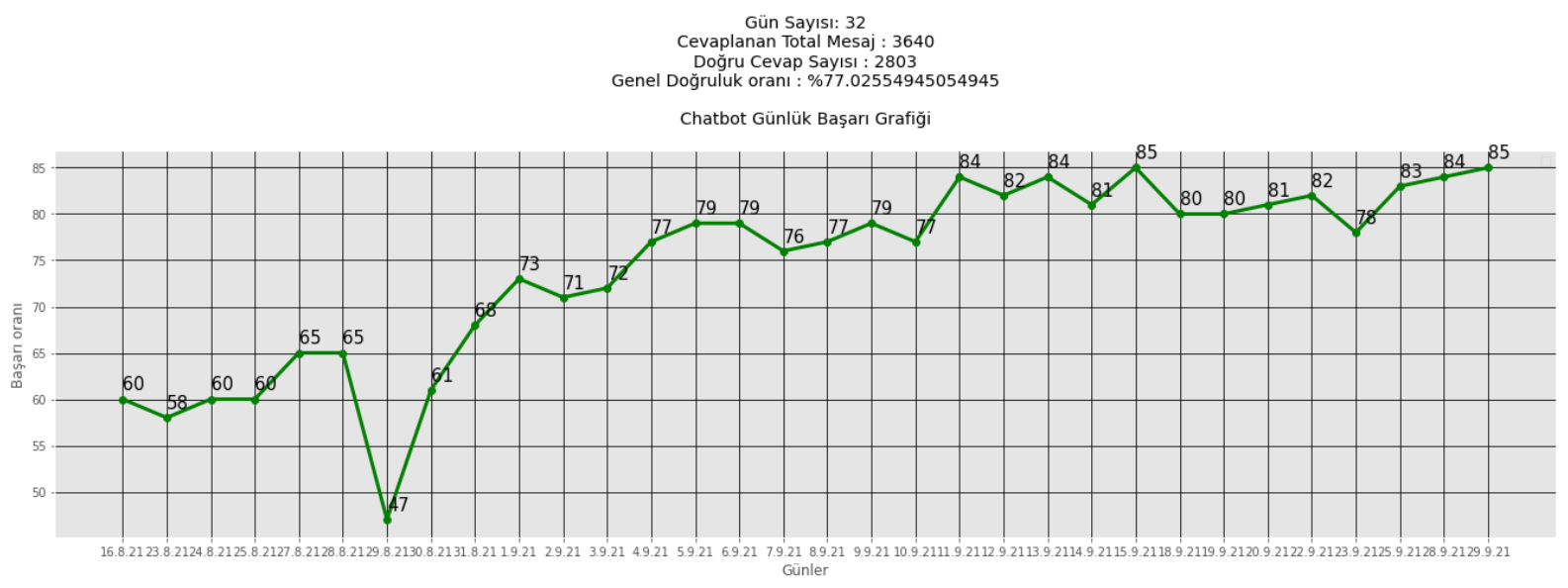

Şekil 6. Chatbot Günlük Başart

32 günlük süreçte Şekil 5' de görüldüğü üzere chatbotun başarısında artış gözlenmektedir. Çalışmanın en başında 2044 adet veri ile eğitilen model, 32 gün sonunda 3470 veri ile eğitilmiştir. 32 gün sonunda chatbot, sorulan toplam 3640 sorunun 2803 tanesine doğru şekilde cevapvermiş ve \%77 lik bir ortalama doğruluk elde edilmiştir.

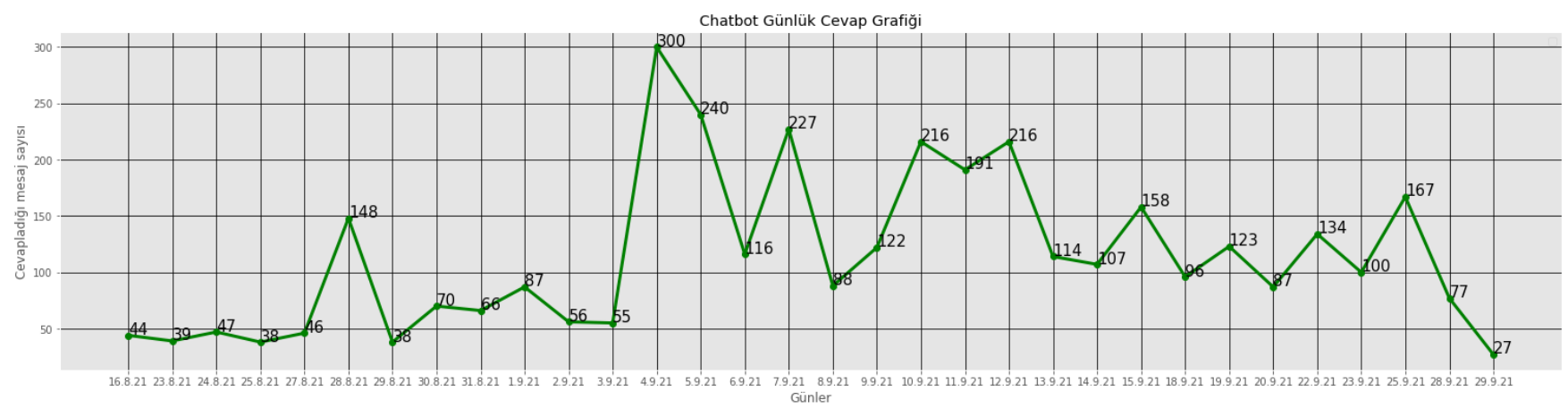

Şekil 7. Chatbot Günlük Cevap

Şekil 6' da ise chatbotun bir günde kaç mesaja cevap verdiği görülmektedir. Özellikle Cuma, Cumartesi ve Pazar günlerinde artış gözükmektedir. Chatbot mesai saatleri dışında devreye alarak çalıştırılmıştır. Akşam saat 20:00 ile 01:00 arasında çalışmaktadır. Cumartesi gününde ise saat 14.00' den Pazartesi saat 01.00’a kadar çalışmaktadır.

Şekil-8, Şekil-9, Şekil-10, Şekil-11 ve Şekil-12'de ise chatbota gerçek kullanıcılardan gelen bazı mesajlar görülmektedir. 


\title{
Avrupa Bilim ve Teknoloji Dergisi
}

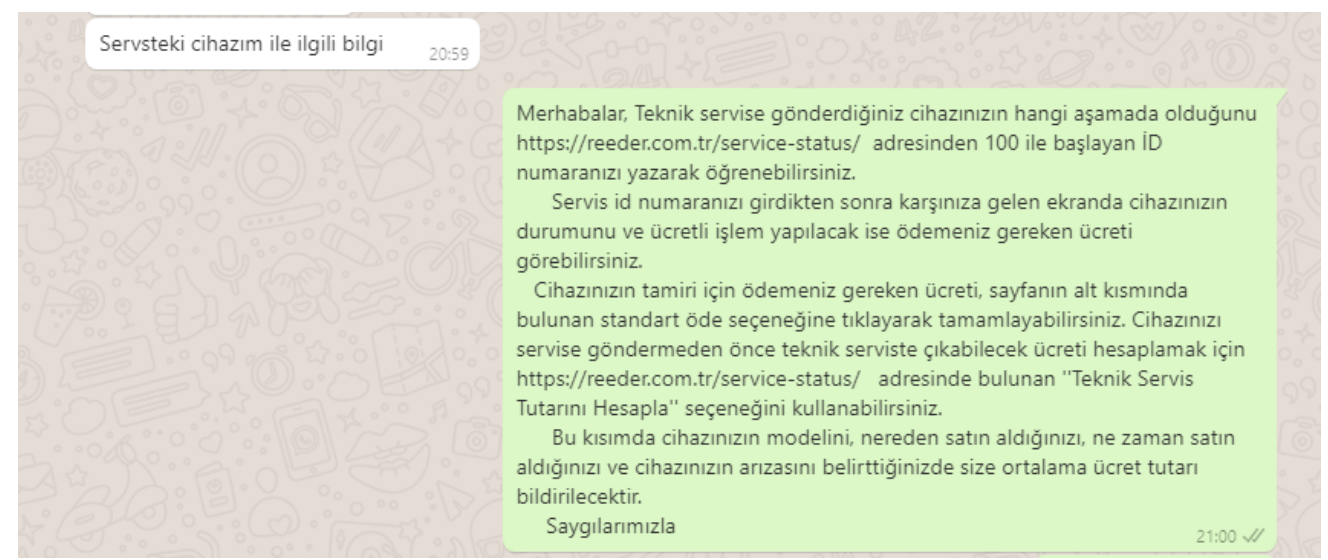

\section{Şekil 8. Örnek Konuşma}

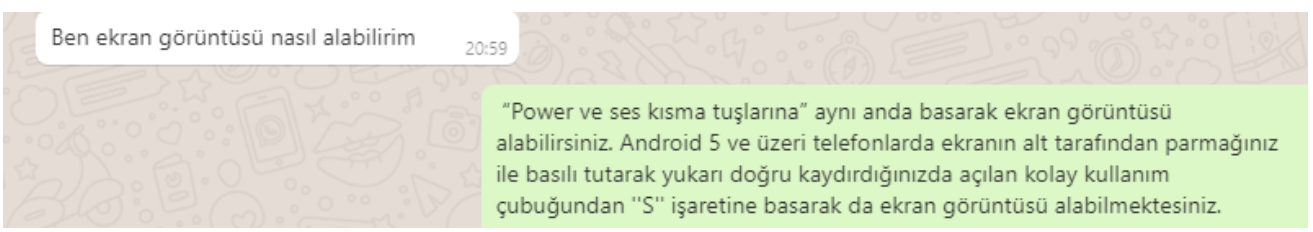

\section{Şekil 9. Örnek Konuşma2}

Saatin kurulumunu yapamıyoruz.en son kademede çocuğun telefon numarasını giriýorum çince bir yazı geliyor baglanamiyoruz

\author{
22,01
}

Uygulamada Türkçe dil desteği bulunmaktadır. Çince bir yazıyla karşılaşma sebepleriniz; 1-Uygulamanın başka bir cihazla bağlantısının bulunması 2-Ağ sorunu olması 3-Hat sorunu olması 4-Uygulamayla cihazın bağlantısının kurulamaması

\section{Şekil 10. Örnek Konuşma3}

\begin{tabular}{l} 
Cihazımı servise göndermek istiyorum \\
$\qquad \begin{array}{l}\text { Merhabalar, Cihazınız P13 Blue serisi ise KVK teknik servis noktalarından } \\
\text { hizmet alabilirsiniz. Cihazınız diğer modellerden biri ise cihazınızı Samsun } \\
\text { servisimize yollamalısınız. Samsun Adresi : Samsun Operasyon Merkezi } \\
\text { Kerimbey Mah. Organize Sanayi Bulvarı No: } 28 \text { Tekkeköy / SAMSUN }\end{array}$ \\
\hline
\end{tabular}

Şekil 11. Örnek Konuşma4

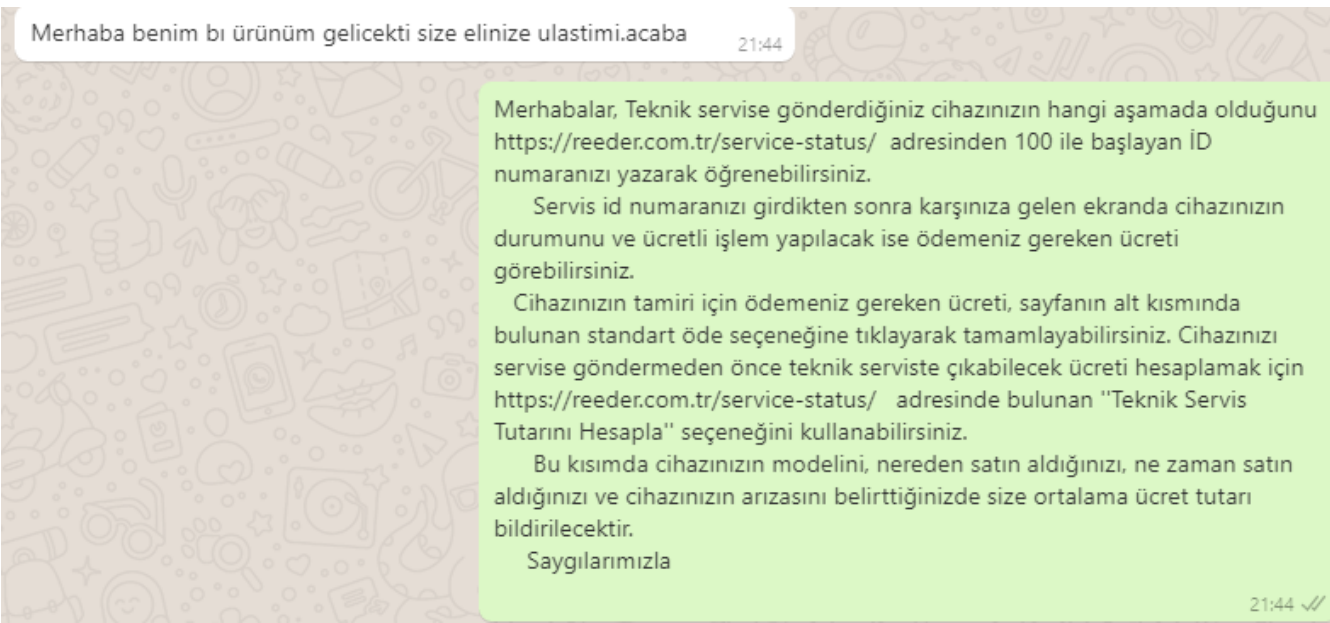


Yukarıdaki grafiklerde görüldüğü üzere Chatbot'un kullanılan modellere göre verdiği doğru cevap yüzdelikleri değişmektedir. 32 günlük chatbot'un gerçek insanlarla denenmesi sonucunda whatsapp üzerinden gelen 3640 adet mesaja cevap vermiştir. Gelen mesajların 2803 adetine doğru cevap vererek ortalama \%77'lik başarı elde edilmiştir. İlk gün(16.08.2021) tarihindeki çalışması sonucunda \%60'lık bir başarı elde edilmiştir. Son günde ise bu başarı $\% 85$ seviyesine gelmiştir. Denemenin son 13 günü \%80'nin üstünde başarı gösterilmiştir. Ortalama günlük 110 mesaj cevaplanmıştır. Chatbot'a verilen model ise 2-3 günde bir veri artırımı sağlanarak yeniden eğitilmektedir. İlk gün veri setinde 2044 veri 340 Kategori bulunmaktadır. Son gün ise veri setinde 3470 veri 480 kategori bulunmaktadır. Veri setinde günlere dayalı olarak düzenli bir artış bulunmaktadır.

\section{Tartışma ve Sonuç}

Yapılan çalışma sonucunda, ticari bir işletmeye ait sıkça sorulan sorular ve müşteri hizmetleri telefon görüşmeleri ve whatsap müşteri hattından gelen veri setiyle eğitimi yapılan chatbot'un kullanıcıların soru ve sorunlarını genel olarak başarıyla karşıladığı gözükmektedir. Çalışmada model başarımı veri setinin giderek büyümesi ve doğru şekilde etiketlenmesi ile artış göstermiştir. $\mathrm{Bu}$ veri artışları görev tabanlı chatbotun kabiliyet ve imkanlarını arttırmıştır. Kilit nokta ise kullanıcıların en fazla sorabilecek veya sordukları sorular üstüne çalışmalar yaparak, bunları veri setine dahil etmek olmuştur. Diğer önemli bir nokta ise kullanıcıyı hem istediği tarzda kısıtlamadan soru sordurabilirken hem de gerektiği durumlarda yönlendirmeler yaparak kullanıcın istediği doğru cevapları almasını sağlanmıştır. Kullanıcıların sorduğu, aynı anlamda olan ama farklı türden sorulara cevap verebilmesi de başarıyı arttıran etkenlerden biri olmuştur. Bu çalışmada gerçekleştirilen chatbot'un tekdüze çalışmanın aksine benzerlerinden ayrıldığı gözükmektedir. Görev tabanlı chatbot olması nedeniyle eğitildiği spesifik konular üzerinde başarıyla cevaplar verdiği ve kullanıcıların sorunlarını çözdüğü gözlemlenmiştir. Diğer görev tabanlı chabotların aksine belirli seçenekler üstünden kullanıcıdan girdi almamakta, kullanıcı daha özgür bir yapıda sorularını sorabilmektedir. $\mathrm{Bu}$ kullanıcının istediği tarzda soru sorma özgürlüğünün temel sebeplerinden biri de chatbot'un çalıştığı ortamın Whatsapp olmasıdır. Tüm bunların yanında chatbotun başarısını düşüren bazı durumlarda olmaktadır. $\mathrm{Bu}$ durumlar bazı kullanıcıların gerektiği durumlarda yapılan yönlendirmelere uymaması, bilgilendirmeleri okumamaları ve chatbot hakkında bilgileri olmamaları veya teknolojiden uzak olmaları, konuştukları kişiyi gerçek bir insan sanmaları başarıyı düşüren bazı faktörlerdendir.

\section{Kaynakça}

[1] A. M. Turing COMPUTING MACHINERY AND INTELLIGENCE

https://academic.oup.com/mind/article/LIX/236/433/986238

[2] Alex Debecker2020 Chatbot Statistics - All The Data You Need https://blog.ubisend.com/optimise-chatbots/chatbotstatistics

[3] Mobile Web Predictions for 2020https://deviceatlas.com/blog/15-mobile-web-predictions2020
[4]- Ming Hsiang Su, Chung Hsien Wu, Kun Yi Huang, Qian Bei Hong, Hsin Min Wang- A chatbot using LSTM-based multilayer embedding for elderly carehttps://researchoutput.ncku.edu.tw/en/publications/achatbot-using-lstm-based-multi-layer-embedding-forelderly-care

[5]- Suzana Ilic',Reiichiro Nakano,Ivo Hajnal-Designing dialogue systems: A mean, grumpy, sarcastic chatbot in the browser- https://arxiv.org/pdf/1909.09531.pdf

[6] Victoria Oguntosin Development of an E-Commerce Chatbot for a University-Shopping-Mallhttps://www.hindawi.com/journals/acisc/2021/6630326/\#int roduction

[7] Ali Hakan ISIK,Ayşenur YAĞCI Sequence to Sequence LSTM Modeli ile Telegram-Bot-Uygulamas1https://dergipark.org.tr/en/pub/gmbd/issue/54119/693071

[8] A. C. Sari, N. Virnilia, J. T. Susanto, K. A. Phiedono, and T. K. Hartono, "Chatbot developments in the business world," Adv. Sci. Technol. Eng. Syst., 2020, doi: 10.25046/aj050676.

[9] S. Roca, J. Sancho, J. García, and Á. Alesanco, "Microservice chatbot architecture for chronic patient support," J. Biomed. Inform., 2020, doi: 10.1016/j.jbi.2019.103305.

[10]S. Hwang and J. Kim, "Toward a chatbot for financial sustainability," Sustain., 2021, doi: 10.3390/su13063173.

[11]M. Dahiya, "A Tool of Conversation: Chatbot," Int. J. Comput. Sci. Engenieering, 2017.

[12]B. A. Shawar and E. Atwell, "ALICE chatbot: Trials and outputs," Comput. y Sist., 2015, doi: 10.13053/CyS-19-42326.

[13]C. Grové, "Co-developing a Mental Health and Wellbeing Chatbot With and for Young People," Front. Psychiatry, 2021, doi: 10.3389/fpsyt.2020.606041.

[14]G. Padmaja, M. S. Begum, A. Chandrika, B. B. Sree, and G. Meghana, "Healthcare Chatbot," UGC Care List. J., 2020.

[15]S. Hamad and T. Yeferny, "A chatbot for information security," arXiv, 2020.

[16]P. A. Tamayo, A. Herrero, J. Martín, C. Navarro, and J. M. Tránchez, "Design of a chatbot as a distance learning assistant," Open Prax., 2020, doi: 10.5944/openpraxis.12.1.1063.

[17]M. H. Tsai, J. Y. Chen, and S. C. Kang, "Ask Diana: A keyword-based chatbot system for water-related disaster management," Water (Switzerland), 2019, doi: 10.3390/w11020234.

[18]D. C. Toader et al., "The effect of social presence and chatbot errors on trust," Sustain., 2020, doi: 10.3390/SU12010256.

[19]Q. Zhi and R. Metoyer, "GameBot: A visualizationaugmented chatbot for sports game," 2020, doi: $10.1145 / 3334480.3382794$.

[20]I. Nica, O. A. Tazl, and F. Wotawa, "Chatbot-based tourist recommendations using model-based reasoning," 2018.

[21]M. H. Tsai, J. Y. Chen, and S. C. Kang, "Ask Diana: A keyword-based chatbot system for water-related disaster management," Water (Switzerland), 2019, doi: 10.3390/w11020234.

[22]P. A. Tamayo, A. Herrero, J. Martín, C. Navarro, and J. M. Tránchez, "Design of a chatbot as a distance learning assistant," Open Prax., 2020, doi: 10.5944/openpraxis.12.1.1063. 
European Journal of Science and Technology 